\title{
Esophageal disorders in horses - a review of literature
}

\author{
Barbora Bezdekova \\ Equine Clinic, Faculty of Veterinary Medicine, University of Veterinary and Pharmaceutical Sciences Brno, Brno, Czech Republic
}

\begin{abstract}
Summary
Esophageal diseases are among the less commonly seen disorders in equine veterinary practice around the world. This paper summarises information on the clinical presentation, diagnostic procedures and specific diseases of the esophagus in the horse. The review includes the description of an esophageal obstruction, esophageal rupture, esophagitis, esophageal strictures, esophageal diverticula, esophageal congenital disorders, megaesophagus and esophageal neoplasia. Medical and surgical treatment of particular esophageal disorders and possible complications are discussed.
\end{abstract}

Keywords: horse / esophagus / choke / esophageal rupture / esophageal stricture / esophageal diverticulum / gastroenterology

\begin{abstract}
Ösophaguserkrankungen des Pferdes - eine Literaturübersicht
Weltweit gesehen sind Erkrankungen der Speiseröhre in der Pferdepraxis eher selten. Die Einleitung dieses Artikels gibt einen Überblick über das relativ typische klinische Bild von Erankungen des Ösophagus. Diagnostische Grundsätze einschließlich klinischer Untersuchung, Endoskopie und bildgebender Verfahren werden diskutiert. Der Hauptteil des Berichtes konzentriert sich auf die Beschreibung der Ätiologie, klinisches Aussehen und die Diagnose spezifischer Erkrankungen des Ösophagus des Pferdes sowie ihre Behandlung und eventuelle Komplikationen. Die einfache Schlundverstopfung ist die häufigste Erkrankung des Ösophagus beim Pferd. Prädisposititon, konservative und chirurgische Therapie aber auch eventuell auftretende Komplikationen werden diskutiert. Des Weiteren wird die potenziell tödliche Ösophagusruptur besprochen, deren Ätiologie, Management und potentielle Komplikationen. Ösophagitis entsteht beim Pferd normalerweise sekundär zu anderen Erkrankungen, weshalb die Behandlung von der Grunderkrankung abhängig ist. Die Therapie sollte auf die Prevention von Ösophagusstrikturen abzielen. Die Ösophagusstrikturen sind beim Pferd in drei Typen unterteilt, entsprechend welcher Teil der Speiseröhrenwand betroffen ist. Sowohl konservative als auch chirurgische Behandlungen werden beschrieben. Zwei Arten von Ösophagusdivertikeln werden beim Pferd beobachtet. Gewöhnlich bedarf nur das echte Divertikel einer chirurgischen Therapie. Erbliche Ösophaguserkrankungen treten selten auf: Duplikationsösophaguszysten, intramurale Inklusionszysten, erbliche Stenosen, persistierender rechter Aortenbogen, idiopatischer Megaösophagus. Der Megaösophagus wird später noch getrennt diskutiert, da Friesen dafür prädisponiert sind. Der letzte Teil des Artikels beschäftigt sich mit dem aktuellen Wissensstand über Neoplasien des Ösophagus.
\end{abstract}

Schlüsselwörter: Pferd / Ösophagus / Würgen / Ösophagusruptur / Ösophagusstriktur / Ösophagusdivertikel / Gastroenterologie

\section{Introduction}

The clinical signs and diagnosis of esophageal disorders and their therapy are specific in horses. Clinical presentation of esophageal obstructive disorders is typically manifested by feed and saliva appearing at the nostrils and mouth, hypersalivation and flapping of the lip. Odynophagia (painful swallowing) and repeated extension of the head and neck could also be present. Affected horses are usually inappetent. Coughing may occur because of feed and water aspiration (Stick 1982, Craig et al. 1989, Fubini et al. 1999, Feige et al. 2000, Fubini 2002). Recurrent signs of esophageal obstruction may indicate a persistent narrowing of the esophagus due to some other anatomic pathology or esophageal dysfunction (Feige et al. 2000, Fubini 2002, Stick 2006).

Diagnosis of esophageal diseases is based on physical examination including passing a nasogastric tube, endoscopy and radiography. Additional information can be obtained via clinical pathology, ultrasound and manometric evaluation (Craig et al. 1989, Stick 2006). Manometry has limited use in equine practice (Stick 2006). Palpation of the laryngeal and cervical region could reveal subcutaneous emphysema or masses. Detailed oral examination can exclude oral causes of dysphagia such as cleft palate or dental diseases. Insertion of a nasogastric tube could confirm impassibility of the esophagus and exact location of an obstruction (Fubini et al. 1999,
Fubini 2002, Stick 2006). Basic clinical pathology in horses with esophageal disease includes packed cell volume (PCV), total plasma protein (TPP) and plasma electrolyte concentrations to determine the horse's metabolic and hydration status (Fubini 2002). Dehydration, neutrophilia, hypochloremia, hyponatremia and hypokalemia are reported to be the most consistent abnormalities accompanying esophageal disorders (Craig et al. 1989). The same authors mentioned metabolic alkalosis was more often detected than metabolic acidosis in horses suffering from esophageal disease probably due to salivary loss.

Endoscopic examination of the upper airways can reveal the presence of feed and saliva in the nasal cavities. If an empyema of the guttural pouches is the reason of regurgitation purulent discharge could be seen at the orifice of diseased guttural pouch. Endoscopy of the trachea could reveal the feed aspiration. Esophagoscopy is an important and essential part of the examination of a horse with suspect esophageal disorder. Esophageal obstruction, mucosal lesions, esophageal strictures, diverticula and other disorders can be diagnosed with this method (Stick 1982, Fubini 2002).

Radiographic examination can visualise the cervical and thoracic esophageal region in the adult horse. It is an important diagnostic procedure in esophageal disorders other than sim- 
ple obstruction (Fubini 2002, Stick 2006). Esophagoscopy and esophageal radiographic contrast studies are necessary before surgery to precisely locate and determine the extent of the condition requiring surgical treatment (Stick 2006). Native radiographic study will confirm the presence of radio-opaque foreign bodies and esophageal and periesophageal gas (Craig et al. 1989, Stick 2006). For a complete examination, contrast oesophagography may be used. Negative contrast study can be performed by air insufflation through a nasogastric tube into the esophagus. Esophageal diverticula and fistula can be visualised by this method. Positive contrast studies are conducted using barium sulphate or iodinated solutions (Stick 1982, Greet and Whitwell 1986, Fubini et al. 1999). Esophageal strictures and diverticula are best evaluated by obtaining a double-contrast oesophagogram (Stick 2006, Waguespack et al. 2007). In cases with suspected esophageal perforation, iodine contrast instead of barium should be used. Thoracic radiography is also indicated in cases suffering from aspiration (Stick 2006).

Esophageal disorders are connected with many complications. Common respiratory complications include aspiration pneumonia, mediastinitis or pleuritis (Craig et al. 1989, Stick 2006). Esophageal mucosal ulcerations are also frequent following esophageal obstructions. Circumferencial mucosal lesions can result in esophageal strictures. Perforation of the esophagus as well as other pathologies (mural abscesses, diverticula etc.) could also follow after esophageal obstruction (Stick 2006, Fubini et al. 1999). Laryngeal hemiplegia and Horner's syndrome can occur especially after esophageal surgery (Craig et al. 1989).

\section{Specific disorders}

\section{Esophageal obstruction}

Esophageal obstruction (choke) is the commonest esophageal disorder in the horse (Stick 1987, Knottenbelt et al. 1992, Fubini 2002, Brever et al. 201 1). The most commonly observed clinical sign in horses with esophageal obstruction is regurgitation. Primary esophageal obstruction (simple choke) is prevalent in horses. It happens following feeding of dry sugar beet, pellets or triturated hay., less frequently pieces of carrots, apples or vegetables (Craig et al. 1989, Feige et al. 2000, Duncanson 2006). Ponies are probably predisposed to simple choke (Fubini 2002, Duncanson 2006). Feed esophageal impaction has been associated with greed and poor dentition (Craig et al. 1989, Hyllier 1995). The most common sites of simple obstruction are the cranial cervical esophagus caused by pieces of apples, the esophagus at the thoracic inlet and the caudal esophageal sphincter in the hiatal area caused by dry sugar beet (Feige et al. 2000, Brever et al. 2011 ). Diagnosis is based on the typical clinical presentation and inability to pass a nasogastric tube into the caudal esophagus. Secondary esophageal obstruction occurs due to other pathology (esophageal stricture, diverticulum, mural or extramural masses etc.) (Craig et al. 1989, Feige et al. 2000, Fubini 2002, Stick 2006, Brever et al. 2011).

Medical management of primary esophageal obstruction is based on prevention of aspiration pneumonia and resolution of the impacted material. The horse with suspect esophageal impaction must not be allowed to eat or drink and it should be kept in relatively stress-free conditions until treatment is initiated. The horse should be sedated to prevent aspiration and improve other therapeutical procedures (Hillyer 1995). In some horses spontaneous resolution of esophageal obstruction may happen with sedation only (Fubini 2002, Duncanson 2006). If spontaneous resolution does not occur, other medicaments including butylscopolamin bromide and metamizol should be applied (Brever et al. 2011). Oxytocin may also have a profound effect on the relaxation of striated muscle of the cranial esophagus and can assist in the alleviation of esophageal obstruction (Hance et al. 1997, Meyer et al. 2000). Conservative treatment with oxytocin is limited to cranial obstructions and non-pregnant animals (Hance et al. 1997). In short term choke patients, gentle esophageal lavage through an inserted nasogastric tube is indicated (Craig et al. 1989, Hillyer 1995, Feige et al. 2000, Stick 2006). During lavage, only warm water must be used and the horse's head should be lowered due to deep sedation. Liquid paraffin is contraindicated because it can cause necrotic pneumonia when aspirated. Craig et al. (1989) reported that recurrent obstructions are common after esophageal lavage, most probably due to following anatomical complications and this decreases long-term survival rates. But a more favorable prognosis following esophageal lavage for treatment of simple choke in horses was reported by Feige et al. (2000) and Brever et al. (2011).

In esophageal obstruction cases lasting several hours or even days, it is recommended to use intravenous hydration supplemented with electrolyte balance in the patient (Jones and Blikslager 2004). Intravenous hydration, along with esophageal relaxans may promote hydration and softening of impact material and help to prevent electrolyte or acid-base imbalances resulting from salivary loss. It leads to resolution of choke in the majority of horses within several hours rarely a few days of treatment are required. Depending on the duration of the obstruction and the degree of complications present (mucosal trauma), hay or grass should be withheld for at 24 hours after resolution of the choke to preclude reobstruction but offer water. After this time, the horse should be fed with soft food and slowly return to a normal feeding regime (Jones and Blikslager 2004).

Surgical therapy for esophageal obstruction is based on oesophagotomy and this procedure is limited to the cervical esophagealesophageal region, it is however connected with risk of postoperative complications (Craig et al. 1989, Stick 2006).

Complications of esophageal obstruction are common and include aspiration pneumonia, esophageal mucosal damage (esophagitis and mucosal ulceration), esophageal stricture and esophageal rupture (Todhunter et al. 1984, Craig et al. 1989, Feige et al. 2000, Stick 2006).

\section{Esophageal rupture}

Esophageal rupture is a rare esophageal disease in horse and can be fatal. The most likely cause is iatrogenic perforation during repeated nasogastric tube insertion. Other causes include longstanding esophageal obstruction, foreign body perforation, sharp or blunt neck trauma and periesophageal abscess ruptures. There is a better prognosis in those patients 
where the cause of perforation was trauma in comparison with those in which esophageal rupture followed long-term esophageal obstruction (Lunn and Peel 1985, Craig et al. 1989, Fubini 2002, Stick 2006). Perforating lesions are mostly found in the cervical esophageal region (Vrins et al. 1983, Lunn and Peel 1985, Craig et al. 1989). Food material in the periesophageal tissues can migrate into the cranial thoracic inlet and cause infection mediastinitis which has poor prognosis. Cranial migration of food material into the pharyngeal area (guttural pouch) in a case with ruptured cervical esophageal diverticulum has been described (Vrins et al. 1983, Fubini 2002, Stick 2006).

Diagnosis of esophageal rupture is based on clinical signs, esophagoscopy and radiographic examination. Clinical signs include edema and emphysema connected with cellulitis of the neck and cranial body in cases with cervical esophageal rupture (Fubini 2002, Stick 2006). These cases could develop serious dyspnea due to tracheal compression as a result of periesophageal accumulation of feed, water and inflammatory exsudation and these patients require acute tracheotomy (Craig et al. 1989, Fubini 2002). Esophagoscopy could reveal accumulation of feed at the rupture site, usually sharp borders of wall disintegrity and sometimes liquid leakage (Fubini 2002, Read et al. 2002). Plain radiographic examination can visualise periesophageal gas. To exclude other disorders (anaerobic periesophageal abscedation, tracheal rupture etc.), positive or double contrast studies using iodine preparation are helpful in the confirmation of esophageal rupture (Fubini 2002, Stick 2006).

Treatment is possible in horses with cervical esophageal rupture in cases where ascendant mediastinitis has not occured. Esophageal perforation healing will have to be by secondary intention following aggressive wound debridement and ventral drainage combined with systemic antibiotic administration (Lunn and Peel 1985, Craig and Todhunter 1987, Stick 2006). The horse must then be fed by placing a nasogastric tube through the rupture site or through a new oesophagotomic wound made distally from the original rupture. Therapeutic treatment and this type of feeding management is a long-term, intensive process, requiring atypical access and is expensive. Esophageal fistulas had healed by day 50 and 80 respectively in two horses in one study (Craig et al. 1989).

\section{Esophagitis}

Esophagitis and mucosal ulceration are an esophageal inflammation which could be caused by gastric reflux (reflux esophagitis), trauma (longstanding food impactions, nasogastric intubation), infection (mural abscess) or chemical injury (historically cantharidin) (Schoeb and Panciera 1979, Hardy et al. 1992, Jones and Blikslager 2004, Stick 2006). Clinical signs of esophagitis and mucosal ulceration are nonspecific and include discomfort during swallowing, hypersalivation and bruxism. Some patients suffering from esophagitis are asymptomatic or only slightly inappetent. Diagnosis is based on esophagoscopy (Jones and Blikslager 2004, Stick 2006, Brever et al. 2011).

Reflux esophagitis occurs relatively frequently in horses with pyloric stenosis due to glandular ulceration (Rebhun et al.
1982). Other probable causes of reflux esophagitis are grass sickness, severe Gasterophilus spp. infestation or idiopatic reflux disease (Gilmore and Jolly 1974, Edens and Murray 1992, Baker et al. 2004). Local longitudinal and circumferential ulcerations occur following esophageal obstructions. Longitudinal mucosal lesions have much better prognosis than circular damage. Circular lesions could lead to esophageal strictures particularly if the lesions are longer than $2 \mathrm{~cm}$ (Todhunter et al. 1984, Stick 2006).

After-choke esophagitis can be treated with non-steroidal anti-inflammatory drugs (NSAIDs) to reduce pain and inflammation and some authors also recommend antibiotics. Oral application of NSAIDs is not recommended (Jones and Blikslager 2004). Brever et al. (2011) described the application prednisolone to reduce fibroblast growth causing scar tissure. An important part of treatment is dietary management which aims to prevent complications such as esophageal strictures (Todhunter et al. 1984, Craig et al. 1989).

\section{Esophageal stricture}

Esophageal stricture can be congenital or acquired. Acquired forms are more common in horses (Fubini 2002). Clinical signs of congenital stenosis appear shortly after birth and strictures appear to involve only the mucosal and submucosal layers of the esophagus (Stick 1987, Clabough et al. 1991, Tillotson et al. 2003). Acquired strictures can be caused by external or internal trauma such as long-term esophageal obstruction which can produce circumferential ulceration or a kick from another horse, nasogastric tube trauma etc. Horse kick injuries usually result in anatomical lesions in the cervical part of the esophagus (Stick 1982, Craig et al. 1989). Strictures can also result from esophageal surgery or esophageal rupture healing (Stick 1982, Fubini et al. 1999). Three main types of esophageal strictures exist in the horse mural lesions which may involve only the adventicia and muscular layers (type 1), esophageal rings or webs which involve only the mucosa and submucosa (type 2) and annular rings which involve all the layers of the esophageal wall (type 3). The cervical esophageal area is the most common site for all types of esophageal strictures with the exception of mucosal rings. Mucosal rings could also occur in the thoracic and abdominal esophagus (Fubini 2002).

Diagnosis of esophageal strictures is based on history, physical examination, esophagoscopy and radiographic contrast studies. Recurrent choke typically occurs. Endoscopically, esophageal strictures appear as a persistent narrowing of the lumen. Suspicious segments of the esophagus should be examined several times by repeated viewing of the area because of the possible false appearance of the stricture being due to swallowing. In some cases stricture prevents the examiner from passing the scope into the distal esophagus and stomach. The best radiographic evaluation is produced by double-contrast oesophagogram (Stick 2006). Mucosal stricture formation can occur from as early as the day 15th after mucosal damage. The greatest narrowing happens between days 30-45, but the esophageal lumen can return to normal by day 60 under conservative management (Todhunter et al. 1984, Knottenbelt et al. 1992, Fubini et al. 1999, Stick 2006). Therefore surgical treatment of type two and three 
esophageal stricture should be delayed until 60 days after the traumatic incident (Fubini 2002, Stick 2006).

Treatment and prognosis of esophageal strictures depends on the stricture type and length of duration. Conservative management of esophageal stricture is aimed at dilation of the stenotic segment. Medical management of strictures includes a slurry type diet and palliative treatment of the clinical signs (antiinflammatory and antimicrobial treatment) (Todhunter et al. 1984, Craig et al. 1989, Knottenbelt et al. 1992). A slurry diet consists of frequent small meals of moistened pellets or fresh grass and leads to natural stricture dilation. Successful conservative management of acute esophageal strictures in all nine horses was described by Todhunter et al. (1984) and Knottenbelt et al. (1992). Use of bougienage, pneumatic or hydrostatic dilators used to have minimal practical value in adult horses because of the limited availability of special equipment and limited experience (Knottenbelt et al. 1992). But Tillotson et al. (2003) described the successful treatment of a one month old foal with possible congenital esophageal stricture using a balloon dilator. Therefore balloon dilator could have a practical value in foals or ponies.

Several surgical approaches can be described for the treatment of esophageal stricture in horses. Surgically managed esophageal strictures have a better long-term survival rate than nonsurgically managed patients (Craig et al. 1989). Selection of the surgical technique is generally based on the type of stricture. The best prognosis is for stricture type 1 (mural lesions which involve only the adventicia and muscular layers). These cases can be successfully treated by esophagomyotomy, esophagomyoplasty or esophagomyotomy with esophagopexy (Craig et al. 1989, Lillich et al. 2001, Stick 2006). Partial esophageal resection (longitudinal esophagomyotomy combined with mucosal resection) is the most appropriate for lesions confined to the mucosa and submucosa (type 2) and annular stenosis (type 3) (Derksen and Stick 1983, Craig and Todhunter 1987). Recurrence of stricture following this procedure may be an indication for complete resection or patch grafting (Stick 2006). Complete esophageal resection and anastomosis is a limited procedure with dubious prognosis. It is possible to use it in horses with stricture type 3 (Craig et al. 1989, Stick 2006). Esophagoplasty, esophageal replacement and mucosal patch grafting have been used in horses in individual cases with limited success (Hoffer et al. 1977, Craig et al. 1989). Fenestration through a cicatrix can be used in a horse with esophageal stricture. This method is used as the final option for surgical repair of an esophageal stricture and it involves esophagostomy followed by fenestration of the mucosal and submucosal cicatrix (Craig and Todhunter 1987, Craig et al. 1989, Fubini 2002).

\section{Esophageal diverticulum}

Esophageal diverticula in horses are an acquired problem and represent local extensions of the esophageal lumen unlike megaesophagus. Two types of esophageal diverticulum can be described, traction or true diverticulum, resulting cranially to stricture of periesophageal fibrous scar tissue and secondly, a pulsion or false diverticulum, resulting from protrusion of mucosa through a defect in the esophageal musculature. Often a traction diverticulum occurs secondary to stricture due to wound healing or previous surgery. Traction diverticulum is usually asymptomatic (Stick 1982, Fubini et al. 1999).

Pulsion diverticula can result from external trauma or by fluctuation of intraesophageal pressure caused by impacted feed (Stick 1982, Craig and Todhunter 1987, Craig et al. 1989, Ford et al. 1991). Clinically painless cervical enlargement is often present in pulsion diverticula presented cranially (Murray and Gaughan 1993). Caudal cervical and thoracic diverticula in horses have been described in a limited number of cases (Fravenfelder and Adams 1982, Ford et al. 1991, Swain et al. 2004, Brever et al. 2011 ). A pulsion diverticulum usually leads to repeated esophageal obstruction and severe chronic mucosal ulceration. Perforation of a pulsion diverticulum is more likely than perforation of a traction diverticulum (Craig et al. 1989, Swain et al. 2004).

Positive contrast radiography will visualise a traction diverticulum as a simple widening of the disabled esophagus. A pulsion diverticulum will appear spherical and flasklike (Stick 1982). Traction diverticulum usually does not need any treatment (Stick 1982, Fubini et al. 1999). Treatment of a pulsion diverticulum involves isolation of the esophagus and inversion of the redundant mucosal sac into the lumen of the esophagus. (Hackett et al. 1978, Stick 1982). Resection of the sac is possible, but with the risk of esophagotomic wound infection and dehiscence (Fravenfelder and Adams 1982, Stick 2006).

\section{Congenital abnormalities}

Esophageal cysts are rare congenital malformations in horses and their embryologic origin must be demonstrated by histologic examination. Cytological examination of the viscous contents may reveal desquamated epithelial cells and keratinaceous debris (Rindermann et al. 2007). Esophageal duplication cysts and intramural inclusion cysts are described in horses (Orsini et al. 1988, Gaughan et al. 1992, Sams et al. 1993, Peek et al. 1995).

Intramural inclusion cysts are located within the esophageal wall and lined by squamous epithelium. Histologically, they are keratinised squamous epithelial inclusion cysts. Characteristically these cysts are not surrounded by the longitudinal and circular esophageal muscle layer. This morphological feature is an essential distinction between inclusion and duplication cysts (Vougiouklakis et al. 2003). Intramural esophageal cysts have been found within the esophageal wall in the cervical esophagus in horses. They cause partial esophageal obstruction and clinical signs include recurrent dysphagia and a palpable soft tissue mass in the neck in some cases (Sams et al. 1993, Stick 2006). The diagnosis using contrast radiography is based on the typical appearance of a filled defect caused by a mural lesion. Surgical treatment includes removal of the cyst following esophagomyotomy or marsupialisation. Marsupialisation of the cyst may be in some cases preferable to surgical removal (Orsini et al. 1988, Sams et al. 1993, Stick 2006).

Esophageal and tracheal duplication cysts are rare congenital malformations in humans and horses (Orsini et al. 1988, Gaughan et al. 1992, Sams et al. 1993, Peek et al. 1995). These cysts are covered with a ciliated respiratory epithelium 
and have a muscular wall similar to that of the esophagus. Clinical signs are similar to those in other forms of esophageal obstruction. A tubular duplication cyst in the cervical esophagus of a foal was successfully treated by surgical excision (Gaughan et al. 1992).

Other congenital esophageal abnormalities are rare in horses. Congenital stenosis, a persistent right aortic arch and idiopatic megaesophagus were reported (Bowman et al. 1978, Rohrbach 1980, MacKey et al. 1986, Clabough et al. 1991, Butt et al. 1998).

\section{Megaesophagus}

Megaesophagus is a chronic dilation of the esophagus and is a rare condition in horses. It is not a specific disease and is associated with several causes. Esophageal obstruction-induced megaesophagus (more common) and esophageal dysfunction-induced megaesophagus (less common) are described in the literature (Broekman and Kuiper 2002).

Esophageal obstruction can lead to esophageal dilation, cranial to the site of the obstruction. Megaesophagus due to simple esophageal feed obstruction is usually reversible (Craig et al. 1989, Broekman and Kuiper 2002).

Dysfunction-induced megaesophagus is most likely to be congenital and it is caused by a generalised motor dysfunction (Bowman et al. 1978, Rohrbach 1980, Rohrbach and Rooney 1980, Greet and Whitwell 1986, Broekman and Kuiper 2002). Megaesophagus following gastric ulceration is more common than the congenital form and represents another type of dysfunction-induced megaesophagus in a horse (Murray et al. 1988). Megaesophagus is also an early sign of equine dysautonomia and may be visible in patients with botulism (Greet and Whitwell 1986, Jones and Blikslager 2004).

The most frequently occurring clinical signs of megaesophagus are lethargy, dysphagia, regurgitation, intermittent esophageal swelling and weight loss (Broekman and Kuiper 2002, Jones and Blikslager 2004). Diagnosis is based on history, clinical signs and contrast radiography. One report mentioned Friesian horses having a strong predisposition for this problem (Broekman and Kuiper 2002). The prognosis for congenital megaesophagus is poor, mainly because of the frequent complication of aspiration pneumonia. Therapy is based on feeding management. This involves long-term feeding of soft food fed at the horse's breast height or keeping the horse at pasture only (Broekman and Kuiper 2002, Stick 2006).

\section{Esophageal neoplasia}

Papers describing esophageal neoplasia in horses are rare. Primary esophageal squamous cell carcinomas with a poor prognosis have been described in a limited number of horses. These tumors have a typical "cauliflower" appearance (Roberts and Kelly 1979, Campbell-Beggs et al. 1993, Brazil 2008). Local extension of a squamous cell carcinoma into the esophagus from a primary gastric lesion is more common (Moore and Kintner 1976, Green et al. 1986, Booth et al. 2008). These cases could be macroscopically (esophagosco- pically) confusing due to the smooth appearance of the pale, thickened esophageal wall which has been infiltrated with neoplastic tissue (Brazil 2008). Endoscopic examination of the esophagus and/or pleural cavaty including with histological examination of a biopsy sample are usually conclusive (Ford et al. 1987, Campbell-Beggs et al. 1993). The use of endoscopically-delivered tissue staining with topical Lugol's iodine (3\%) and Toluidin blue (1\%) has been described (Green 1992). Lugol's iodine stains normal mucosa but not inflamed or neoplastic tissue whereas Tolvidin blue will stain early squamous cell carcinoma lesions.

Gastric leiomyosarcoma can extend from the stomach into the distal esophagus in the horse (Boy et al. 1992). Differential diagnosis of esophageal neoplasia could be exuberant granulation tissue or an esophageal abscess (Erkert et al. 2002). Non-neoplastic disorder - idiopathic muscular hypertrophy of the esophagus (IMHO), is reported in horses (Benders et al. 2004). IMHO is probably an underdiagnosed disease with questionable clinical importance in horses.

\section{Conclusion}

Esophageal disorders are not commonly seen in equine veterinary practice, the exception being simple obstruction. Clinical signs accompanying esophageal obstructive diseases are typical (regurgitation) and a usually determinant for diagnosis. In more complicated esophageal disorders, diagnostic procedures, including endoscopy and radiography can exactly localise the lesion. Medical management is recommended in uncomplicated chokes and some other esophageal problems. Surgery of the esophagus is limited but it is a crucial pathway for certain diseases of the equine esophagus. Equipment, clinical experience and patience are usually required for a successful outcome in equine esophageal disorders. Prognosis frequently depends on other possible complications.

\section{Acknowledgement}

This paper was supported by the Ministry of Education, Youth and Sports of the Czech Republic (Project No. VZ MSM $6215712403)$.

\section{References}

Baker S. J., Johnson P. J., David A. and Cook C. R. (2004) Idiopathic gastresophageal reflux disease in an adult horse. J. Am. Vet. Med. Assoc. 224, 1967-1970

Benders N. A., Veldhuis Kroez E. J. and van der Kolk J. H. (2004) Idiopathic muscular hypertrophy of the esophagus in the horse: a retrospective study of 31 cases. Equine Vet. J. 36, 46-50

Booth T. M., Marmion W. J., Cullimore A. M. and Finnie J. W. (2008) Esophageal obstruction in an aged pony associated with squamous cell carcinoma. Equine Vet. Educ. 20, 627-631

Bowman K. F., Vaughan J. T., Quick C. B., Hankes G. H., Redding R. W., Purohit R. C., Rumph P. F., Powers R. D. and Harper N. K. (1978) Megaesophagus in a colt. J. Am. Vet. Med. Assoc. 172, 334-337

Boy M. G., Palmer J. E., Heyer G. and Hamir A. N. (1992) Gastric leiomyosarcoma in a horse. J. Am. Vet. Med. Assoc. 200, 1363-1364

Brazil T. J. (2008) Recurrent esophageal obstruction caused by gastro-esophageal squamous carcinoma: a diagnostic challenge for the clinician? Equine Vet. Educ. 20, 633-634 
Brever J., Böttcher D., Reischaver A., Müller K., Spallek K., Recknagel S. Uhlig A. and Schusser G. F. (2011) Retrospektive Analyse von 74 Pferden mit Krankheiten des Esophagus. Pferdeheilkunde 27, 15-27

Broekman L. E. M. and Kuiper D. (2002) Megaesophagus in the horse. A short review of the literature and 18 own cases. Vet. $Q$. 24, 199-202

Butt T. D., MacDonald D. G., Crawford W. H. and Dechant J. E. (1998) Persistent right aortic arch in a yearling horse. Can. Vet. J. 39, $714-715$

Campbell-Beggs C. L., Kiper M. L., MacAllister C., Henry G. and Roszel J. F. (1993) Use of esophagoscopy in the diagnosis of esophageal squamous cell carcinoma in a horse. J. Am. Vet. Med. Assoc. 202, 617-618

Clabough D. L., Roberts M. C. and Robertson I. (1991) Probable congenital esophageal stenosis in a thoroughbred foal. J. Am. Vet. Med. Assoc. 199, 483-485

Clark E. S., Morris D. D. and Whitlock R. H. (1987) Esophageal dysfunction in a weanling thoroughbred. Cornell Vet. 77, 151-160

Craig D.R. and Todhunter R.J. (1987). Surgical repair of an esophageal stricture in a horse. Vet. Surg. 16, 251-254

Craig D. R., Shivy D. R., Pankowski R. L. and Erb H. N. (1989) Esophageal disorders in 61 horses. Results of nonsurgical and surgical management. Vet. Surg. 18, 432-438

Derksen F. J. and Stick J. A. (1983) Resection and anastamosis of esophageal stricture in a foal. Equine Pract. 5, 17-20

Duncanson G. R. (2006) Equine esophageal obstruction: a long term study of 60 cases. Equine Vet. Educ. 8, 336-340

Edens L. M. and Murray M. J. (1992) Gastro-esophageal reflux in a weanling filly: association with Gasterophilus spp. infestation. Equine Gastroenterol., Equine Vet. J. Suppl. 13, 26-28

Erkert R. S., MacAllister C. G., Higbee R., Moll H. D., Reiners S. Crowson C., Bahr R. and Bartels K. E. (2002) Use of a neomydium:yttrium-aluminium-garnet laser to remove exuberant granulation tissue from the esophagus of a horse. J. Am. Vet. Med. Assoc. 221, 403-407

Feige K., Schwarzwald C., Fürst A. and Kaser-Hotz B. (2000) Esophageal obstruction in horses: a restrospective study of 34 cases. Can. Vet. J. 41, 207-210

Ford T. S., Vaala W. E., Sweeney C. R., Skand D. and Saik J. E. (1987) Pleuroscopic diagnosis of gastresophageal squamous cell carcinoma in a horse. J. Am. Vet. Med. Assoc. 190, 1556-1558

Ford T. S., Schumacher J., Chafin M. K., Vacek J., Brumbaugh G. W. and Crossland L. E. (1991) Surgical repair of an intrathoracic esophageal pulsion diverticulum in a horse. Vet. Surg. 20, 316-319

Fravenfelder H. C. and Adams S. B. (1982) Esophageal diverticulectomy in a horse. J. Am. Vet. Med. Assoc. 180, 771-772

Fubini S. L., Starrak G. S. and Freeman D. E. (1999) Esophagus. In: Equine Surgery, 2nd edn., Eds: J. A. Auer, J. A. Stick, WB Saunders, Philadephia. pp 199-209

Fubini S. L. (2002) Esophageal diseases. In: Manual of Equine Gastroenterology, 1st edn., Eds: T. Mair, T. Divers, N. Ducharme, WB Saunders, London. pp 89-98

Gaughan E. M., Gift L. J. and Frank R. K. (1992) Tubular duplication of the cervical portion of the esophagus in a foal. J. Am. Vet. Med. Assoc. 201, 748-750

Gilmour J. S. and Jolly G. M. (1974) Some aspects of the epidemiology of equine grass sickness. Vet. Rec. 95, 77-81

Green S., Green E. M. and Aronson E. (1986) Squamous cell carcinoma: an unusual cause of choke in a horse. Mod. Vet. Pract. 65, 870-875

Green E. M. (1992) Esophageal obstruction. In: Current Therapy in Equine Medicine, 3rd edn, Ed: N.E. Robinson, WB Saunders, Philadelphia. pp 175-184

Greet T. R. C. and Whitwell K. E. (1986) Barium swallow as an aid to the diagnosis of grass sickness. Equine Vet. J. 18, 294-297

Hackett R. P., Dyer R. M. and Hoffer R. E. (1978) Surgical correction of esophageal diverticulum in a horse. J. Am. Vet. Med. Assoc. $173,998-1000$

Hance S. R., Noble J., Holcomb S., Rush-Moore B. and Beard W. (1997) Treating choke with oxytocin. Proc. 43rd Ann. Conv. Am. Assoc. Equine Practnrs. Phoenix, Arizona, December 7 to 10 , 1997. pp 338-339

Hillyer M. (1995) Management of esophageal obstruction (choke) in horses. In Pract. 17, 450-457

Hoffer R. E., Barber S. H., Kallfelz F. A. and Petro S. P. (1977) Esophageal patch grafting as a treatment for esophageal stricture in a horse. J. Am. Vet. Med. Assoc. 171, 350-353

Jones S. L. and Blikslager A. T. (2004) Esophageal Diseases. In: Equine internal medicine, 2nd edn., Eds: S.M. Reed, W.M. Bayly, D.C. Sellon, WB Saunders, Elsevier, St. Louis. pp 855-863
Knottenbelt D. C., Harrison L. J. and Peacock P. J. (1992) Conservative treatment of esophageal stricture in five foals. Vet. Rec. 131, 27-30

Lillich J. D., Frees K. E., Warrington K., Van Harreveld P. D., Gaughan E. M. and Beard W. L. (2001) Esophagomyotomy and esophagopexy to create a diverticulum for treatment of chronic esophageal stricture in 2 horses. Vet. Surg. 30, 449-453

Lunn D. P. and Peel J. E. (1985) Successful treatment of traumatic esophageal rupture with severe cellulitis in a mare. Vet. Rec. 116, 544-545

MacKey V. S., Large S. M., Breznock E. M. and Arnold J. S. (1986) Surgical correction of a persistent right aortic arch in a foal. Vet. Surg. 15, 325-328

Meyer G. A., Rashmir-Raven A., Helms R. J. and Brashier M. (2000) The effect of oxytocin on contractility of the equine esophagus: a potential treatment for esophageal obstruction. Equine Vet. J. 32, 151-155

Moore J. N. and Kintner L. D. (1976) Recurrent esophageal obstruction due to squamous cell carcinoma in a horse. Cornell Vet. 66, 590-597

Murray M. J., Ball M. M. and Parker G. A. (1988) Megaesophagus and aspiration pneumonia secondary to the gastric ulceration in a foal. J. Am. Vet. Med. Assoc. 192, 381-383

Murray R. C. and Gaughan E. M. (1993) Pulsion diverticulum of the cranial cervical esophagus in a horse. Can. Vet. J. 34, 365-367

Orsini J. A., Sepesy L., Donawick W. J. and McDevitt D. (1988) Esophageal duplication cyst as a cause of choke in the horse. J. Am. Vet. Med. Assoc. 193, 474-476

Peek S. F., De Lahunta A. and Hackett R. P. (1995) Combined esophageal and tracheal duplication cyst in an Arabian filly. Equine Vet. J. 27, 475-478

Read E. K., Barber S. M., Wilson D. G., Bailey J. V. and Naylor J. M. (2002) Esophageal rupture in a Quarter Horse mare: unique features of liquid enteral hyperalimentation and fistula management. Equine Vet. Educ. 14, 126-130

Rebhun W. C., Dill S. G. and Power H. T. (1982) Gastric ulcers in foals. J. Am. Vet. Med. Assoc. 180, 404-407

Rindermann G. F., Velde K. and Nagy A. D. (2007) What is your diagnosis? J. Am. Vet. Med. Assoc. 230, 1465-1466

Roberts M. C. and Kelly W. R. (1979) Squamous cell carcinoma of the lower cervical esophagus in a pony. Equine Vet. J. 11, 199-201

Rohrbach B. W. and Rooney J. R. (1980) Congenital esophageal ectasia in a Thoroughbred foal. J. Am. Vet. Med. Assoc. 177, 65-67

Sams A. E., Weldon A. D. and Rakestraw P. (1993) Surgical Treatment of Intramural Esophageal Inclusion Cysts in Three Horses. Vet. Surg. 22, 135-139

Schoeb T. R. and Panciera R. J. (1979) Pathology of blister beetle (Epicauta) poisoning in horses. Vet. Pathol. 16, 18-31

Stick J. A. (1982) Surgery of the esophagus. Vet. Clin. North Am. Large Anim. Pract. 4, 33-59

Stick J. A. (1987) Esophageal disease. In: Current therapy in Equine Medicine, 2nd edn., Ed: N.E. Robinson, WB Saunders, Philadelphia. pp 12-15

Stick J. A. (2006) Esophagus. In: Equine Surgery, 3rd edn., Eds: J.A. Auer, J.A. Stick, WB Saunders, Elsevier, St. Louis. pp 351-374

Swain J. M., McGorum B. C., Scudamore C. L. and Pirie R. S. (2004) Persistent esophageal obstruction (choke) associated with a diverticulum of the terminal esophagus in a pony. Equine Vet. Educ. 16, 195-198

Tillotson K., Traub-Dargatz J. L. and Twedt D. (2003) Ballon dilation of an esophageal stricture in a one-month-old Appaloosa colt. Equine Vet. Educ. 15, 67-71

Todhunter R. J., Stick J. A., Trotter G. W. and Boles C. (1984) Medical management of esophageal stricture in seven horses. J. Am. Vet. Med. Assoc. 185, 784-787

Vougiouklakis T., Mitselou A., Dallas P., Peschos D., Stefanou D., loa chim E., Charalabopoulos K. and Agnantis N. (2003) Inclusion cyst of esophagus: Case report and review of the literature. Exp. Oncol. 25, 22-24

Vrins A., O'Brien T. R. and Carlson G. (1983) Diverticulum and fistula of the lower cervical esophagus in a horse. Can. Vet. J. 24, 385-387

Waguespack R. W., Bolt D. M. and Hubert J. D. (2007) Esophageal Strictures and Diverticula. Compendium: Equine Ed. 2, 194-206

Barbora Bezdekova, DVM, PhD., Dipl.ECEIM

Equine Clinic, Faculty of Veterinary Medicine

University of Veterinary and Pharmaceutical Sciences Brno

Palackeho 1-3

61242 , Brno

Czech Republic

bbezdekova@vfu.cz 